\title{
Employment outcome and predictors of competitive employment at two-year follow-up of a vocational rehabilitation program for individuals with schizophrenia in a high-income welfare society
}

\author{
Stig Evensen ${ }^{1 *}$ \\ Torill Ueland ${ }^{1,2}$, Associate Professor \\ June Ullevoldsæter Lystad ${ }^{1}$ \\ Helen Bull $^{1}$ \\ Ole Klungsøyr ${ }^{1,3}$, Senior scientist \\ Egil W Martinsen ${ }^{1,4}$, Professor \\ Erik Falkum ${ }^{1,4}$, Professor
}

Word count:

3596

Word count abstract:

242

\footnotetext{
${ }^{1}$ Department of Research, Division of Mental Health and Addiction, Oslo University Hospital, Oslo, Norway

${ }^{2}$ Department of Psychology, University of Oslo, Oslo, Norway

${ }^{3}$ Oslo Centre for Biostatistics and Epidemiology, Oslo University Hospital, Oslo, Norway

${ }^{4}$ Department of Clinical Medicine, University of Oslo, Oslo, Norway

*To whom correspondence should be addressed; Division of Mental Health and Addiction, Oslo University Hospital, Bygg 12, Gaustad Sykehus, PO Box 4956, Nydalen, 0424 Oslo, Norway; tel: 47-45-43-28-85, e-mail: stig.evensen@ medisin.uio.no
} 


\title{
Abstract
}

Background: Employment is an important part of recovery for individuals with schizophrenia. The employment rate for this group is as low as $10 \%$ in Norway and major system related barriers to employment are evident.

\begin{abstract}
Aims: This study reports the competitive employment outcome at two-year follow-up of a vocational rehabilitation study augmented with cognitive remediation (CR) or elements from cognitive behaviour therapy (CBT) for individuals with schizophrenia spectrum disorders. It also investigates if global functioning, self-esteem and depression at baseline predicts employment outcome, and if change in these variables during the intervention period is associated with employment outcome.
\end{abstract}

Method: 148 participants with schizophrenia spectrum disorders in six Norwegian counties received ten months vocational rehabilitation augmented with either CBT $(n=84)$ or CR ( $n=64)$. Both competitive and sheltered workplaces were used. Participants were assessed at baseline, at the end of the intervention period and at two-year follow-up.

Results: At two-year follow-up 21.2\% had obtained competitive employment. A further $25.3 \%$ had work placements in competitive workplaces. We found significant improvements in global functioning, self-esteem and depression during the intervention period, but no significant differences between the two intervention groups. High baseline global functioning and self-esteem, as well as positive change in these variables during the intervention period, were significantly associated with higher competitive employment outcome at two-year follow-up.

Conclusion: The results add to existing evidence that competitive employment is attainable for individuals with schizophrenia. High global functioning and self-esteem was strongly associated with competitive employment outcome. 
Key words: Schizophrenia, Vocational Rehabilitation, Global Functioning, Self-Esteem, Employment Outcome. 


\section{Background}

Employment is an important part of recovery for individuals with schizophrenia (1) and is positively associated with higher quality of life $(2,3)$. Despite this, international reviews have found employment rates between $6 \%$ and $39 \%(4,5)$. The corresponding rate in Norway is $10 \%$ (6), and individuals who receive disability benefits rarely transfer into employment (7). The high unemployment rates generate a significant burden both for the individual, their families (8) and for society at large, with indirect costs of unemployment accounting for $45 \%$ of the total costs associated with schizophrenia (6). It should therefore be of great interest to decision makers and service providers to develop interventions that can help individuals with schizophrenia obtain employment, and identify factors that affect the likelihood of successful employment outcome.

The barriers to employment for individuals with schizophrenia have been studied with somewhat inconclusive results. One review emphasized that limited access to supported employment services and fragmented health and disability policies were the main barriers to employment (9), while another review of 62 relevant studies concluded that neurocognition, negative symptoms, young age, education and work history were also significant predictors of competitive employment outcome (10). An international study of 1379 schizophrenia patients found that persistent psychotic symptoms (negative more than positive) were associated with poor functional outcome (11). Remission from negative and positive symptoms was also identified as a major predictor for functional outcome in a study of first episode psychosis patients (12). Several studies of supported employment for individuals with severe mental illnesses have identified improvements in global functioning, depression and self-esteem in individuals who have obtained competitive employment (13-15). These studies have, however not identified any significant associations between baseline values on these variables and competitive employment outcome $(10,14,16,17)$. It is challenging to compare study findings 
as different definitions of functional outcome and competitive employment are being used.

One study, for example, defined successful competitive employment outcome as a minimum of one day at work during an 18 month follow-up period (16). In another study average employment rates in the intervention group were $28.3 \%$, but only $3 \%$ earned enough income to support themselves without social security benefits (18). The lack of a unified definition of competitive employment may explain the lack of significant associations between baseline global functioning and competitive employment in the literature.

Although no direct link between self-esteem and occupational status has been identified, self-esteem has a positive effect on job satisfaction (19) and the ability to persist at difficult tasks (20). High self-esteem also predicts rapid re-employment after job loss in the general population (21). In addition, there is strong evidence that low self-esteem is a significant predictor of depression (22), which is strongly associated with unemployment both in general (23-25) and following a supported employment program(26). Global functioning, self-esteem and depression can be easily assessed using readily available instruments in clinical practice. The inconsistencies in the literature regarding predictors of successful employment outcome in the schizophrenia population warrants further investigation.

Norwegian vocational rehabilitation services are generally outsourced by the Norwegian Labour and Welfare Administration (NAV) to agencies that provide both sheltered work and supported employment. It is important to note that the supported employment offered in most cases is combined with other social security schemes in terms of NAV paying the individuals' salary for extended periods, or the clients being offered work placements with no additional salary beyond their disability benefits (27). This practice, in addition to limited access to supported employment services, ineffective vocational services based in sheltered enterprises and generous disability benefits, are likely contributing factors to the low employment rate among individuals with schizophrenia spectrum disorders in Norway $(6,7$, 
27). In this context the Job Management Program (JUMP) was established as a vocational rehabilitation (VR) program earmarked for individuals with schizophrenia spectrum disorders. The project had a subsidiary aim of providing access to vocational services, and an overall aim of aiding participants obtain competitive employment. The program consisted of ten months VR services where both competitive and sheltered workplaces were used. Supported employment with the limitations described above was the available method of follow up, and efforts were made to integrate mental health services and VR services through a formalised collaboration where employment specialists were supervised by an experienced mental health professional. The VR was augmented with cognitive behaviour therapy (CBT) techniques twice a week over a six-month period for one group. The other group received VR augmented with cognitive remediation (CR) over the same time frame (28). At the start of the intervention all participants were reliant on social security benefits, and $17 \%$ had some form of employment (29). At ten- month follow-up $8.1 \%$ had obtained competitive work, $35.8 \%$ had work placements and $32.5 \%$ had sheltered work.

\section{Aims}

The main objectives of the present study were to assess the competitive employment outcome of the JUMP- study at two- year follow- up, and to examine whether global functioning, selfesteem and depression at baseline predicted competitive employment or unemployment at two-year follow-up. We also wanted to study the developments in the same variables during the intervention period and examined the change in scores and their association with competitive employment or unemployment at two-year follow-up. Due to the extensive use of work placement in Norwegian rehabilitation services, we also report results for this employment outcome. 


\section{Material and Methods}

The present study is part of the JUMP study, a multi-site vocational rehabilitation (VR) program for adults with schizophrenia spectrum disorders in Norway. Efforts were made to integrate mental health services and VR services through formalised collaborations where employment specialists were supervised by experienced mental health professionals.

The participants were offered 10-month VR within the established services where prevocational training, work placements and sheltered work has been the common approach (27, 30). The VR consisted of assessments of skills, experience and job preferences. Further, help was provided in preparing resumes, practicing job interviews, establishing contact with employers, and obtaining work placements, sheltered work or competitive employment. Onthe-job skills training, task adaptations and employer support was also provided when necessary. The VR was augmented with (1) sustained support and close collaboration between the participant and all involved parties, that is, employment specialists, general practitioners, mental health workers, employers, and social and vocational services; (2) psychoeducation (symptoms, course, treatment, prevention, rehabilitation and prognosis) geared at the project teams, participants, and in some cases employers and colleagues; and (3) three counties were randomized to augment the VR with CR and the other 3 were randomized to augment the VR with CBT techniques. Participants were given the intervention provided in their catchment area twice a week over a six-month period (28). The CR and CBT interventions were carried out by trained employment specialists.

The JUMP study was approved by the Regional Committee of Medical Research Ethics and The Norwegian Data Protection Authority (ClinicalTrials.gov identifier NCT01139502). 


\section{Participants}

Participants were recruited from local mental health centres and vocational services within the six catchment areas. Self-referral was also possible. All participants provided written informed consent. The inclusion criteria were age between 18 and 65 years, an IQ above 70, a diagnosis within the Diagnostic and Statistical Manual of Mental Disorders, Fourth Edition (DSM-IV) (31) criteria for a broad schizophrenia spectrum disorder, and adequate understanding of the Norwegian language. Exclusion criteria were head injury with unconsciousness for more than ten minutes or requiring medical treatment, neurological disorders, IQ below 70, unstable or uncontrolled medical conditions interfering with cognitive function, and a score of 3 or above on items 1-3 (alcohol or substance abuse, violent behaviour and suicidal ideation) on the Health of the Nation Outcome Scales (HoNOS) (32). Participants were required to understand and speak Norwegian (33).

A total of 319 persons were referred to the JUMP study. Of these, 76 did not meet the inclusion criteria and 61 declined, mainly due to lack of motivation, poor timing or reluctance to participate in research. Another nine did not complete the assessments and 25 did not start the vocational rehabilitation after assessment. The remaining 148 participants were included in the study between August 2009 and March 2012, 84 and 64 respectively allocated to the CBT and CR interventions (Figure 1).

Insert figure 1 about here

\section{Clinical assessments}

Diagnoses were determined at baseline using the Norwegian version of the M.I.N.I PLUS (34) modules A, C, D, K, L, and M, by clinicians trained in the use of this instrument. Global 
functioning, self-esteem and depression were measured at baseline, at the end of the intervention and at a two-year follow-up using: the Global Assessment of Function, split version (GAF-S and GAF-F)(35); the Rosenberg Self-Esteem Scale (RSE) (36); and the Calgary Depression Scale for Schizophrenia (CDSS) (37). GAF-S and GAF-F were scored by health professionals trained and experienced in the administration of these outcome measures. The CDSS was scored by the same trained mental health professionals in a structured interview. RSE was administered as a self-report measure.

\section{Demographic variables}

Gender, age, highest completed education, and past work experience (competitive and sheltered) were included as descriptive variables in the present study. Duration of illness (DOI) was recorded as the number of years from the patient's first contact with specialist mental health services for psychotic symptoms. The defined daily dose (DDD) of antipsychotics was recorded according to the WHO (38).

\section{Outcome measures}

Employment status was recorded as competitive employment, work placement, sheltered work or unemployed. Each participant's employment status was recorded at baseline, at the end of the intervention period and at two-year follow-up. In the logistic regression analyses examining the predictive value of GAF, RSE and CDSS, competitive employment and unemployment were used as dependent variables. CDSS was used as a dichotomous variable. Scores of 6 or higher were considered to indicate major depression in line with past studies $(39,40)$. Competitive employment was defined as at least 5 hours of paid work per week.

\section{Statistical analysis}

IBM SPSS Statistics version 21.0 (41) was used for statistical analyses. Independent samples t-tests were used to examine group differences on employment outcome and change scores on GAF, RSE and CDSS. All significance tests were two-tailed with a significance level of 5\%. Multiple logistic regressions were undertaken to determine the associations between 
predictors and employment outcome, and linear regressions were undertaken to examine predictors for working hours and work tenure.

\section{Results}

\section{Baseline analyses}

One hundred and forty eight individuals were included at baseline. There were significant differences between the CBT and CR intervention groups at baseline with respect to gender $\left(X^{2}(1, \mathrm{n}=148)=3.88, \mathrm{p}=.049\right)$ and duration of illness $(t(143)=2.08, \mathrm{p}=.040)($ Table 1$)$ only.

Insert table 1 about here

\section{Employment outcome}

We found no significant differences between the two intervention groups in employment outcome, hours worked or work tenure between the end of the intervention period and twoyear follow-up. Among the 148 individuals who commenced the program, none had competitive employment with wages as their primary source of income at baseline. Two individuals died prior to two-year follow-up of causes unrelated to participation in the study. At two-year follow-up $21.2 \%(n=31)$ of the participants had competitive employment. In this group the mean hours of work per week was 28.5 (SD 10.81) and the work tenure since the end of the intervention period was 13.2 months (SD 4.29). Twenty-four (16.4\%) had wages as their primary source of income, while 7 (4.8\%) earned a part-time wage and had social security benefits as their primary source of income. In addition, 25.3\% ( $n=37)$ had work placements in ordinary workplaces at two-year follow-up. The mean hours of work per week in this group was 19.7 (SD 9.01) and the work tenure since the end of the intervention 
period was 11.7 months (SD 5.02). An additional 13.7\% $(n=20)$ had sheltered work at twoyear follow-up with mean working hours per week being 12.2 (SD 5.79) and work tenure of 13 months (SD 4.8). The remaining 39.2\% (n=58) were unemployed. Seven participants could not be reached at the two-year follow-up. The loss to follow-up of these subjects was managed conservatively by classifying them as unemployed at the end of the intervention period.

With employment in competitive settings being the primary focus of the current study, linear regression analyses were performed for work tenure and weekly working hours for those who had competitive employment and work placements at two-year follow-up. Independent variables entered in the regressions were: intervention group (CBT and CR); gender; age; DOI; baseline and change scores for RSE, GAF-S, GAF-F and CDSS. The model was significant and explained $17 \%$ of the variance in work tenure. Baseline RSE (beta $=.56$; $\mathrm{p}=.005)$, GAF-S $($ beta $=-.54 ; \mathrm{p}=.041)$ GAF-F $($ beta $=.45 ; \mathrm{p}=.007)$ and RSE-change (beta $=.50 ; \mathrm{p}=.005)$ made significant contributions to the model. The model was not significant for working hours.

\section{Depression}

No significant associations were found between CDSS and competitive employment, work placement or unemployment outcome. There were small but significant improvements in CDSS score during the intervention period $($ mean $=.7 ; \mathrm{SD}=2.89 ; 95 \% \mathrm{CI}=.20,1.2 ; \mathrm{df}=$ $125 ; \mathrm{p}=.007)$. The change was not associated with employment outcome and there were no significant differences between the two intervention groups.

\section{Global functioning and self-esteem association with competitive employment}

Strong associations were found between competitive employment at two-year follow-up and baseline scores, as well as change scores between baseline and the end of the intervention period on for both GAF and RSE (Table 2). Each scale was modelled separately with 
coefficients for baseline and change, and adjusted for age, gender, duration of illness and intervention group (CBT and CR). Model fit was confirmed with Hosmer - Lemeshow Goodness of fit test for all three models with significance levels of .79, .77 and .29.

Significant improvements were identified for GAF-S (mean 3.59; SD $=10.3 ; 95 \% \mathrm{CI}=1.79$, 5.39; df = 128; $\mathrm{p}<.001), \mathrm{GAF}-\mathrm{F}($ mean 5.34; $\mathrm{SD}=11.8 ; 95 \% \mathrm{CI}=3.29,7.40 ; \mathrm{df}=128 ; \mathrm{p}<$ .001 ) and RSE (mean 1.0; $\mathrm{SD}=4.24 ; 95 \% \mathrm{CI}=1.76,2.62 ; \mathrm{df}=122 ; \mathrm{p}=.01$ ), but no significant differences were found between the intervention groups. The variables were standardized (original variable divided by its standard-deviation) for ease of interpretation. The associations were of similar magnitude for baseline and change scores of GAF-S and represent more than doubled odds for competitive employment per standard deviation. The association was even stronger for baseline and change scores on GAF-F. RSE had weaker, but still significant associations at baseline, and borderline significant associations for change score (Table 2).

Insert table 2 about here

The change scores were negatively correlated with baseline scores for both GAF ( $\mathrm{S}$ and F) and RSE, suggesting that low odds of competitive employment due to low baseline scores can be compensated for by a similar increase in change scores.

\section{Global functioning and self-esteem association with work placement}

We performed the same analyses for work placement as we did for competitive employment.

No significant associations between baseline scores or change scores were found for GAF, CDSS or RSE. 


\section{Global functioning and self-esteem association with unemployment}

Unemployment at two-year follow-up was significantly associated with baseline scores on

GAF-F, and RSE. Change scores between baseline and the end of intervention were also significantly associated with unemployment for GAF-S (DiffGAF-S $=$ GAF-S $\left.1-\mathrm{GAF}_{1} \mathrm{~S}_{0}\right)$ and GAF-F (adjusted for age, gender, duration of illness and intervention group) (Table 3). No significant relationship was found between change in RSE and unemployment. Standardized variables indicated significant protective effects for both baseline and change scores on GAFS. The associations were of similar magnitude for GAF-F.

Insert table 3 about here

\section{Discussion}

Two years following inclusion in the JUMP study $21.2 \%$ of the participants had gained competitive employment with an average of 28.47 hours worked per week and average work tenure of 13.22 months. In addition $25.3 \%$ had work placements in ordinary workplaces with an average of 19.74 hours of work per week and work tenure of 11.7 months. We also found that $13.7 \%$ had sheltered work where they worked an average of 12.2 hours per week with 13 months work tenure. Work tenure was predicted by higher scores on global functioning and self-esteem at baseline and by positive change in self-esteem.

Although competitive employment was the primary outcome, the Nordic model of vocational rehabilitation services has a strong tradition of using work placements for extended periods as a means of obtaining competitive employment. In this tradition, supported employment is typically provided as an add-on service to traditional forms of VR (i.e. prevocational training, work placements and sheltered work), and the employment specialists have a more generalist role than in specialised supported employment programs (27). In an 
evaluation of work placements as many as $96 \%$ of the employers reported that clients did a good or satisfactory job, yet the work placement rarely led to paid employment (27). The employment outcome results of the JUMP study should be viewed in this framework, and although only $21.2 \%$ of the participants obtained competitive employment, as many as $46.5 \%$ worked in ordinary workplaces with pay or social security benefits at two-year follow-up. For many of the participants who had work placements in ordinary workplaces, the lack of competitive employment was probably not due to their work function, but rather a result of external barriers to competitive employment.

However, high baseline global functioning and self-esteem, as well as positive change on these variables during the intervention period, were significantly associated with higher competitive employment outcome and lower unemployment at two-year follow-up. No such associations were found for the group that had work placements at two-year follow-up, indicating that individual factors at baseline contributed to the type of employment outcome. Whereas GAF baseline and change scores were equally strong predictors of competitive employment, unemployment at two-year follow-up was primarily predicted by the change scores. One explanation of this difference may be the design of the study allowing for both sheltered and competitive employment. It is likely that those with negative change in global functioning more often worked in sheltered settings, and that support services were less likely to be continued at the end of the intervention period, which would affect the employment rate for this group. The associations with unemployment were, however, weaker than the associations with competitive employment, and the reasons why almost $40 \%$ of the participants returned to unemployment is likely multifaceted.

The improvements in global functioning and self-esteem in individuals who obtained competitive employment are in line with past studies (13-15). The strong association between competitive employment outcome and baseline global functioning and self-esteem, however, 
contrasts to past supported employment studies $(14,16)$. This may be due to methodological differences such as differences in defining competitive employment. Also, the current study utilised both sheltered and competitive workplaces. This may have affected the rate of individuals who gained competitive employment, which was lower in our study. There are also major system related barriers to employment in Norway, such as fragmented services and strong employment protection legislation, that hinder individuals on disability benefits from returning to competitive employment, even if they are in remission or have recovered from their illness $(27,42,43)$. The predictive relevance of GAF-F is questionable as the score is partially based on occupational functioning. In our sample it does, however, illustrate the system related barriers to employment, as $10 \%$ of the participants had GAF-F scores above 61 points at baseline, which is indicative of only moderate impairment for study or occupation, yet they did not earn wages.

We identified significant improvements in GAF, RSE and CDSS during the intervention period for both the CBT and the CR intervention groups, but no significant differences between the groups. This was also the case for employment outcome. Past studies report superior outcome for both CR and CBT when merged with supported employment (44, 45). Our results may indicate that the CBT and CR augmented vocational rehabilitation interventions in the JUMP study were equally effective in terms of enabling a significant proportion of the participants to attain competitive employment. The similar improvements in global functioning, self-esteem and depression between the intervention groups supports this argument. It is also likely that the help participants received in overcoming the system related barriers to employment played an equally large role as the specific interventions (9). Due to the lack of a control group however, these conclusions remain speculative.

We interpret the negative correlation between GAF baseline and change scores as a ceiling effect, where those with low baseline scores had a larger potential for improvement. 


\section{Strengths and weaknesses}

A major strength of this study is that employment outcome was established at two-year follow-up for a relatively large sample of individuals with schizophrenia spectrum disorders, who have participated in a novel vocational rehabilitation program in a high income welfare society. The most important weakness of the study is the lack of a control group receiving standard vocational rehabilitation services, which makes it challenging to disentangle specific effective elements in the program.

\section{Conclusion}

The results of this study add to existing evidence that competitive employment is attainable for substantial proportion individuals with schizophrenia in a high-income welfare society with significant system related barriers to employment and a 90\% unemployment rate within the demographic group. We found that high global functioning and self-esteem are strongly associated with competitive employment outcome, and low baseline odds of employment can be compensated for by improvements in global functioning and self-esteem. Improving employment outcome is associated with increased global functioning and higher self-esteem, and is clearly beneficial both to the afflicted person and to society at large in terms of reduced reliance on the social security system.

\section{Acknowledgments}

The authors thank all participants who took part in the study and all their collaborators for making this research possible.

\section{Disclosures}

This work was supported by The Norwegian Directorate of Health (14/4607-13), the Norwegian Labour and Welfare Administration, The South Eastern Norway Health Authority (9297), and The National Council for Mental Health/Health and Rehabilitation (2008/2/0310).

The authors declare no conflict of interest. 


\section{References}

1. McGurk SR, Mueser KT, DeRosa TJ, Wolfe R. Work, recovery, and comorbidity in schizophrenia: a randomized controlled trial of cognitive remediation. Schizophr Bull. 2009;35:319-35. 2. Alonso J, Croudace T, Brown J, Gasquet I, Knapp MR, Suarez D, et al. Health-related quality of life (HRQL) and continuous antipsychotic treatment: 3-year results from the Schizophrenia Health Outcomes (SOHO) study. Value Health. 2009;12:536-43.

3. Bouwmans C, de Sonneville C, Mulder CL, Hakkaart-van Roijen L. Employment and the associated impact on quality of life in people diagnosed with schizophrenia. Neuropsychiatr Dis Treat. 2015;11:2125-42.

4. Jonsdottir A, Waghorn G. Psychiatric disorders and labour force activity. Ment Health Rev J. 2015;20:13.

5. Davidson M, Kapara O, Goldberg S, Yoffe R, Noy S, Weiser M. A Nation-Wide Study on the Percentage of Schizophrenia and Bipolar Disorder Patients Who Earn Minimum Wage or Above. Schizophr Bull 2016;42:443-7.

6. Evensen S, Wisloff T, Lystad JU, Bull H, Ueland T, Falkum E. Prevalence, Employment Rate, and Cost of Schizophrenia in a High-Income Welfare Society: A Population-Based Study Using Comprehensive Health and Welfare Registers. Schizophr Bull. 2016;42:476-83.

7. OECD. Mental Health and Work: Norway. 2013.

8. von Kardorff E, Soltaninejad A, Kamali M, Eslami Shahrbabaki M. Family caregiver burden in mental illnesses: The case of affective disorders and schizophrenia - a qualitative exploratory study. Nord J Psychiatry. 2016;70:248-54.

9. Bond GR, Drake RE. Predictors of competitive employment among patients with schizophrenia. Curr Opin Psychiatry. 2008;21:362-9.

10. Tsang HW, Leung AY, Chung RC, Bell M, Cheung WM. Review on vocational predictors: a systematic review of predictors of vocational outcomes among individuals with schizophrenia: an update since 1998. Aust N Z J Psychiatry. 2010;44:495-504.

11. Haro JM, Altamura C, Corral R, Elkis H, Evans J, Malla A, et al. Understanding the impact of persistent symptoms in schizophrenia: Cross-sectional findings from the Pattern study. Schizophr Res. 2015;169:234-40.

12. Jordan $G$, Lutgens $D$, Joober $R$, Lepage $M$, lyer $S N$, Malla $A$. The relative contribution of cognition and symptomatic remission to functional outcome following treatment of a first episode of psychosis. J Clin Psychiatry. 2014;75:566-72.

13. Burns T, Catty J, White S, Becker T, Koletsi M, Fioritti A, et al. The impact of supported employment and working on clinical and social functioning: results of an international study of individual placement and support. Schizophr Bull. 2009;35:949-58.

14. Mueser KT, Becker DR, Torrey WC, Xie H, Bond GR, Drake RE, et al. Work and nonvocational domains of functioning in persons with severe mental illness: a longitudinal analysis. J Nerv Ment Dis. 1997;185:419-26.

15. Luciano A, Bond GR, Drake RE. Does employment alter the course and outcome of schizophrenia and other severe mental illnesses? A systematic review of longitudinal research. Schizophr Res. 2014;159:312-21.

16. Catty J, Lissouba P, White S, Becker T, Drake RE, Fioritti A, et al. Predictors of employment for people with severe mental illness: results of an international six-centre randomised controlled trial. Br J Psychiatry. 2008;192:224-31.

17. Drake RE, Mueser KT, Torrey WC, Miller AL, Lehman AF, Bond GR, et al. Evidence-based treatment of schizophrenia. Curr Psychiatry Rep. 2000;2:393-7.

18. Drake RE, Frey W, Bond GR, Goldman HH, Salkever D, Miller A, et al. Assisting Social Security Disability Insurance beneficiaries with schizophrenia, bipolar disorder, or major depression in returning to work. Am J Psychiatry. 2013;170:1433-41.

19. Orth U, Robins RW, Widaman KF. Life-span development of self-esteem and its effects on important life outcomes. J Pers Soc Psychol. 2012;102:1271-88. 
20. Baumeister RF, Campbell JD, Krueger JI, Vohs KD. Does High Self-Esteem Cause Better Performance, Interpersonal Success, Happiness, or Healthier Lifestyles? Psychol Sci Public Interest. 2003;4:1-44.

21. Solove E, Fisher GG, Kraiger K. Coping with Job Loss and Reemployment: A Two-Wave Study. J Bus Psychol. 2015;30:529-41.

22. Sowislo JF, Orth U. Does low self-esteem predict depression and anxiety? A meta-analysis of longitudinal studies. Psychol Bull. 2013;139:213-40.

23. Kaspersen SL, Pape K, Vie GA, Ose SO, Krokstad S, Gunnell D, et al. Health and unemployment: 14 years of follow-up on job loss in the Norwegian HUNT Study. Eur J Public Health. 2016;26:312-7.

24. Lamberg $\mathrm{T}$, Virtanen $\mathrm{P}$, Vahtera J, Luukkaala T, Koskenvuo M. Unemployment, depressiveness and disability retirement: a follow-up study of the Finnish HeSSup population sample. Soc Psychiatry Psychiatr Epidemiol. 2010;45:259-64.

25. Rizvi SJ, Cyriac A, Grima E, Tan M, Lin P, Gallaugher LA, et al. Depression and employment status in primary and tertiary care settings. Can J Psychiatry. 2015;60:14-22.

26. Nygren U, Markstrom U, Bernspang B, Svensson B, Hansson L, Sandlund M. Predictors of vocational outcomes using individual placement and support for people with mental illness. Work. 2013;45:31-9.

27. Spjelkavik $\varnothing$. Supported Employment in Norway and in the other Nordic countries. J Vocat Rehabil. 2012;37:163-72.

28. Lystad JU, Falkum E, Haaland VO, Bull H, Evensen S, Bell MD, et al. Neurocognition and occupational functioning in schizophrenia spectrum disorders: The MATRICS Consensus Cognitive Battery (MCCB) and workplace assessments. Schizophr Res. 2016;170:143-9.

29. Bull H, Ueland T, Lystad JU, Evensen S, Martinsen EW, Falkum E. Vocational Functioning in Schizophrenia Spectrum Disorders: Does Apathy Matter? J Nerv Ment Dis. 2016;204:599-605.

30. Hagen B, Härkääpää K, Spjelkavik $\varnothing$. Supported Employment in the Nordic countries. Oslo: Work Research Institute (AFI), 2011.

31. APA. Diagnostic and Statistical Manual of Mental Disorders: DSM-IV1994.

32. Wing JK, Curtis RH, Beevor AS. HoNOS: Health of the Nation Outcome Scales: Report on Research and Development July 1993-December 1995. London: Royal College of Psychiatrists. 1996.

33. Bull H, Ueland T, Lystad JU, Evensen S, Friis S, Martinsen EW, et al. Validation of the work behavior inventory. Nord J Psychiatry. 2015;69:300-6.

34. Sheehan DV, Lecrubier Y, Sheehan KH, Amorim P, Janavs J, Weiller E, et al. The MiniInternational Neuropsychiatric Interview (M.I.N.I.): the development and validation of a structured diagnostic psychiatric interview for DSM-IV and ICD-10.J Clin Psychiatry. 1998;59 Suppl 20:22-33; 457.

35. Endicott J, Spitzer RL, Fleiss JL, Cohen J. The global assessment scale. A procedure for measuring overall severity of psychiatric disturbance. Arch Gen Psychiatry. 1976;33:766-71.

36. Rosenberg M. Society and the Adolescent Self-image. Princeton, NJ: Princeton University Press; 1965.

37. Addington D, Addington J, Schissel B. A depression rating scale for schizophrenics. Schizophr Res. 1990;3:247-51.

38. WHO. World Health Organization: WHO Collaborating Centre for Drug Statistics Methodology. ATC/DDD index 2011. 2011.

39. Sonmez N, Rossberg JI, Evensen J, Barder HE, Haahr U, Ten Velden Hegelstad W, et al. Depressive symptoms in first-episode psychosis: a 10-year follow-up study. Early Interv Psychiatry. 2016;10:227-233.

40. Martin-Reyes M, Mendoza R, Dominguez M, Caballero A, Bravo TM, Diaz T, et al. Depressive symptoms evaluated by the Calgary Depression Scale for Schizophrenia (CDSS): genetic vulnerability and sex effects. Psychiatry Res. 2011;189:55-61.

41. IBM. IBM SPSS Statistics for Windows. 21.0 ed. Armonk, NY: IBM Corp; 2012.

42. OECD. OECD Employment Outlook 2004. Paris: OECD Publishing; 2004.

43. OECD. Mental Health and Work: Norway2013. 
44. Lysaker PH, Davis LW, Bryson GJ, Bell MD. Effects of cognitive behavioral therapy on work outcomes in vocational rehabilitation for participants with schizophrenia spectrum disorders. Schizophr Res. 2009;107:186-91.

45. McGurk SR, Mueser KT, Feldman K, Wolfe R, Pascaris A. Cognitive training for supported employment: 2-3 year outcomes of a randomized controlled trial. Am J Psychiatry. 2007;164:437-41. 
Tables and Figures

Figure 1: Subject flow in the JUMP study; referrals, baseline, post intervention and follow-up assessments 


\section{CBT $(N=\quad$ CR $(N=64) \quad$ Test Statistics
84) \\ Group \\ comparison \\ (p)}

\section{Diagnosis}

Schizophrenia

Schizoaffective disorder

$\begin{array}{lll}90.4 \% & 86.0 \% & \\ 6.0 \% & 9.4 \% & X^{2}(4, \mathrm{n}=148)= \\ 1.2 \% & 3.1 \% & 4.16 \\ 2.4 \% & 1.6 \% & \\ 61.8 \% & 79.4 \% & X^{2}(1, \mathrm{n}=148)= \\ & & 3.88\end{array}$

ns

Psychosis NOS

Delusional disorder

Gender, male

Ethnicity

Caucasian

Other

$\begin{array}{lll}84.5 \% & 93.5 \% & X^{2}(1, \mathrm{n}=148)= \\ 15.5 \% & 6.5 \% & 3.04\end{array}$

ns

\section{Education, highest}

\section{completed}

\begin{tabular}{|c|c|c|c|c|c|c|}
\hline Primary school & \multicolumn{2}{|c|}{$31.0 \%$} & \multicolumn{2}{|c|}{$32.8 \%$} & & \\
\hline High school & \multicolumn{2}{|c|}{$33.3 \%$} & \multicolumn{2}{|c|}{$34.4 \%$} & & \\
\hline Trade school & \multicolumn{2}{|c|}{$9.5 \%$} & \multicolumn{2}{|c|}{$14.1 \%$} & $X^{2}(5, \mathrm{n}=148)=$ & \\
\hline College & \multicolumn{2}{|c|}{$15.5 \%$} & \multicolumn{2}{|c|}{$14.1 \%$} & 2.99 & ns \\
\hline University & \multicolumn{2}{|c|}{$8.3 \%$} & \multicolumn{2}{|c|}{$4.7 \%$} & & \\
\hline \multirow[t]{2}{*}{$\begin{array}{l}\text { Not completed primary } \\
\text { school }\end{array}$} & \multicolumn{2}{|c|}{$2.4 \%$} & & & & \\
\hline & Mean & SD & Mean & $S D$ & & \\
\hline Age & 33.2 & 8.0 & 32.4 & 7.9 & $t(\mathrm{n}=148)=0.62$ & ns \\
\hline $\begin{array}{l}\text { Units of } \text { DDD }^{b} \text { main } \\
\text { anti-psychotic }\end{array}$ & 1.1 & 0.7 & 1.1 & 1.0 & $t(140)=0.13$ & ns \\
\hline $\begin{array}{l}\text { Duration of illness, years } \\
\text { (DOI) }\end{array}$ & 8.1 & 6.8 & 5.9 & 5.5 & $t(143)=2.08$ & .040 \\
\hline $\begin{array}{l}\text { Previous work } \\
\text { experience, months }\end{array}$ & 65.74 & $\begin{array}{l}65.5 \\
2\end{array}$ & 65.17 & $\begin{array}{l}75.2 \\
5\end{array}$ & $t(n=146)=0,05$ & ns \\
\hline Negative symptoms & 16.19 & 5.74 & 15.84 & 5.57 & $t(n=141)=0.37$ & ns \\
\hline \multicolumn{7}{|l|}{ GAF } \\
\hline $\mathbf{S}$ & 51.6 & 9.5 & 54.0 & 11.2 & $t(148)=-1.4$ & ns \\
\hline $\mathbf{F}$ & 51.0 & 8.6 & 49.7 & 10.3 & $t(148)=0.83$ & ns \\
\hline RSE & 27.73 & $\begin{array}{l}5.6 \\
2\end{array}$ & 27.85 & 5.29 & $t(142)=-1.2$ & ns \\
\hline CDSS & 3.48 & $\begin{array}{l}3.7 \\
9\end{array}$ & 4.26 & 3.91 & $t(144)=-1.2$ & ns \\
\hline
\end{tabular}


Table 2: Competitive employment at follow-up, predicted by baseline and change in

GAF-S, GAF-F, and RSE (three separate models), by logistic regression ( $N=125)$.

Confounder adjustment by age*, gender, duration of illness, and intervention group (CR \& CBT)

\begin{tabular}{|c|c|c|c|}
\hline & OR & $95 \% \mathrm{CI}$ & $\mathrm{P}$ \\
\hline GAF-S ${ }_{0}$ & 2.77 & $1.50,5.12$ & 0.001 \\
\hline Diff GAF-S & 2.70 & $1.55,4.69$ & $<0.001$ \\
\hline GAF-F 0 & 3.44 & $1.80,6.57$ & $<0.001$ \\
\hline Diff GAF-F & 3.58 & $1.88,6.83$ & $<0.001$ \\
\hline $\mathrm{RSE}_{0}$ & 2.18 & $1.25,3.82$ & 0.006 \\
\hline Diff RSE & 1.80 & $0.99,3.24$ & 0.051 \\
\hline
\end{tabular}

\footnotetext{
*younger age was significant predictor for competitive employment in models for GAF-S and GAF-F
} 
Table 3: Unemployment at follow-up, predicted by baseline and change in GAF-S, GAFF, and RSE (three separate models), by logistic regression $(\mathrm{N}=125)$. Confounder adjustment by age, gender, duration of illness, and intervention group (CR \& CBT)

\begin{tabular}{r|ccc}
\multicolumn{1}{c}{ OR } & $95 \%$ CI & P \\
\hline GAF-S $_{0}$ & 0.68 & $0.43,1.09$ & 0.107 \\
Diff GAF-S & 0.46 & $0.27,0.76$ & 0.003 \\
\hline GAF-F $_{0}$ & 0.21 & $0.09,0.46$ & $<0.001$ \\
Diff GAF-F & 0.15 & $0.07,0.33$ & $<0.001$ \\
\hline RSE $_{0}$ & 0.65 & $0.41,1.03$ & 0.06 \\
Diff RSE & 0.68 & $0.42,1.08$ & 0.1 \\
\hline
\end{tabular}

